\section{UV-Junkies}

$\mathrm{n}$ den USA haben Epidemiologen eine neue, vor allem unter Jugendlichen beliebte gesundheitsschädliche Droge ausgemacht: den Solariumbesuch. Einer Querschnittsstudie zufolge besuchten $20 \%$ von 1.275 befragten Jugendlichen durchschnittlich 24,3-mal im Jahr ein Sonnenstudio. Besonders die Jüngeren unter 13 Jahren nahmen im Vergleich zu den älteren über 16 Jahren signifikant häufiger eine künstliche Sonnendusche und hatten größere Schwierigkeiten, mit dem UV-Konsum aufzuhören. Der von ihnen angegebene Grund: Die Strahlen heben die Stimmung und wirken ent-

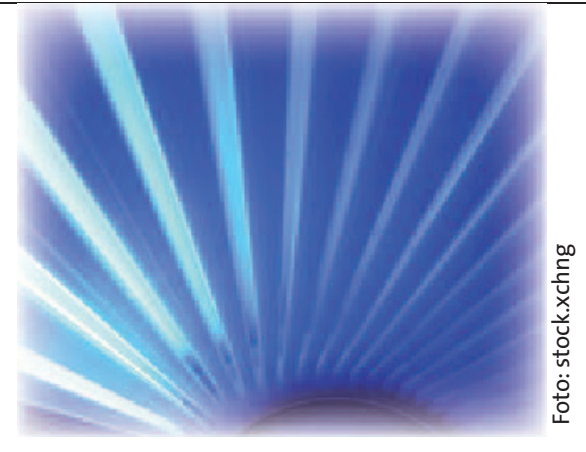

spannend. Dabei gilt es mittlerweile als gesichert, dass Solarien auch durch den hohen UVA-Anteil die DNA der Keratinozyten schädigen und das Risiko für die Entwicklung maligner Hauttumoren erhöhen - vor allem jüngere Menschen sind gefährdet.

$b k$

Zeller S et al. J Am Acad Dermatol 2006; 54: 589-96

\title{
Neurodermitis oder Kontaktekzem?
}

$\mathrm{E}^{\mathrm{n}}$ noxolon (Glycyrrhetinsäure) wird aufgrund seiner antientzündlichen Wirkung in Hautpflegeprodukten verwendet. Bisher sind drei Fälle einer Kontaktallergie gegen Enoxolon beschrieben worden. Vielleicht liegt die Inzidenz aber erheblich höher, vermuten die Autoren eines weiteren Fallberichts: Ein siebenjähriges Mädchen mit einer atopischen Dermatitis entwickelte in den Ellenbeugen juckende erythematöse Maculae genau an den Stellen, wo sie eine Feuchtigkeitscreme aufgetragen hatte. Ein Epikutantest mit der verdächtigen Creme zeigte eine positive Reaktion an den Tagen zwei

\section{Hypoallergener Fisch}

W enn wir Fisch verzehren, nehmen wir überwiegend weißes Muskelfleisch auf. Es enthält bei den meisten Speisefischen das potenziell allergen wirkende Eiweiß Parvalbumin, ein kalziumbindendes Protein mit einem Molekulargewicht von $12 \mathrm{kDa}$. Über die Allergenität des in weit geringeren Mengen vorkommenden dunklen oder auch roten Fischmuskelfleisches, das meist unter der Haut lokalisiert ist und dem Fisch überwiegend für Dauerschwimmaktionen dient, war bisher wenig bekannt. Japanische Forscher haben nun in molekularbiologischen Experimenten herausge- und drei, nach sechs Wochen durchgeführte Tests mit Einzelbestandteilen des Produkts ergaben dann eine singuläre Sensibilisierung gegen Enoxolon. Vermutlich wurde die Enoxolon-Absorption durch die trockene Haut des Mädchens begünstigt, der Kontaktsensibilisierung wurde so der Weg gebahnt. Es ist zu vermuten, dass eine nicht unerhebliche Zahl von Kontaktekzemen durch Enoxolon als atopische Ekzeme fehlgedeutet werden.

$b k$

Oiso $\mathbf{N}$ et al. Contact Dermatitis 2006; 54: 351

funden, dass dieses dunkle Muskelfleisch zwar auch Parvalbumin enthält, allerdings in sehr viel geringeren Konzentrationen als das weiße Fleisch. Dementsprechend geringer ist auch sein allergenes Potenzial. Zusätzlich erbrachte die Untersuchung auch noch ein interessantes praktisches Ergebnis: Sowohl das weiße als auch das dunkle Fleisch der Makrelenart Seriola quinqueradiata enthält praktisch kein Parvalbumin und wird meist auch von Patienten mit einer Fischallergie gut vertragen.

$b k$

Kobayashi A et al. Allergy 2006; 61: 357-63

\section{Wer haftet für Asthma?}

E in Vater machte für das chronische Asthma bronchiale seiner beiden Kinder seine Vermieterin, eine Wohnungsbaugesellschaft, verantwortlich: 1999 habe es einen Rohrbruch gegeben, seitdem sei die Wohnung feucht und von Schimmelpilzen befallen. Schon bald nach diesem Ereignis seien die ersten Atemwegsinfektionen bei den Kindern aufgetreten. Eine Schimmelpilzallergie habe schließlich das Asthma ausgelöst. Obwohl er von der Vermieterin mehrmals gefordert habe, etwas gegen den Schimmel zu unternehmen, sei nichts geschehen. Für die Folgen müsse sie die Kinder nun mit Schmerzensgeld entschädigen.

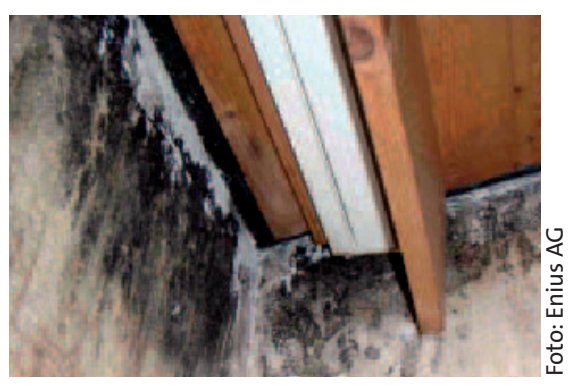

Schimmelbefall einer Wohnung könne durchaus zur Haftung des Vermieters führen, betonte das Kammergericht in Berlin, im konkreten Fall jedoch nicht: Zum einen sei es nicht plausibel, dass Räume nach einem Wasserschaden nicht austrockneten, zum anderen sei nicht jeder Schimmelpilzbefall gesundheitsgefährdend. Der Mieter hätte bei seinen Beschwerden klarstellen müssen, dass er ernste gesundheitliche Schäden befürchtete. Vor April 2003 habe er die Vermieterin jedoch nicht einmal darüber informiert, dass es um Kleinkinder gehe, die weniger widerstandsfähig seien als Erwachsene. Dann hätte sie den Mangel sofort beseitigen lassen müssen. Vernünftigerweise hätte der Vater schon 1999 per Klage auf Abhilfe dringen und das Gesundheitsamt einschalten müssen. Wegen des gesundheitlichen Risikos hätte er auch fristlos den Mietvertrag kündigen können. Er sei aber erst ausgezogen, als die Erkrankung der Kinder schon unheilbar gewesen sei. Das könne er nicht der Vermieterin anlasten.

gri 